\title{
Integrating Personalized Care Planning into Primary Care: a Multiple-Case Study of Early Adopting Patient-Centered Medical Homes
}

\author{
Rendelle E. Bolton, MPH, MSW, MA ${ }^{1,2}$, Barbara G. Bokhour, PhD ${ }^{1,3}$, \\ Timothy P. Hogan, $P h D^{1,4}$, Tana M. Luger, $P h D, M P H^{1,5}$, Mollie Ruben, $P h D^{6,7}$, and \\ Gemmae M. Fix, PhD ${ }^{1,3}$
}

\begin{abstract}
${ }^{1}$ Center for Evaluating Patient-Centered Care in VA, Center for Healthcare Organization and Implementation Research, Edith Nourse Rogers Memorial Veterans Hospital, Memorial Veterans Hospital US Department of Veterans Affairs, Bedford, MA, USA; ${ }^{2}$ Heller School for Social Policy and Management, Brandeis University , Waltham, MA , USA; ${ }^{3}$ Department of Health Law, Policy, and Management, Boston University School of Public Health , Boston, MA , USA; ${ }^{4}$ Division of Health Informatics and Implementation Science, Department of Population and Quantitative Health Sciences, University of Massachusetts Medical School , Worcester , MA , USA; ${ }^{5}$ Department of Health Policy and Management, Fielding School of Public Health, University of California Los Angeles, Los Angeles, CA, USA; ${ }^{\circ}$ Department of Psychology, University of Maine , Orono , ME , USA; ${ }^{7}$ Center for Healthcare Organization and Implementation Research, Boston VA Healthcare System, US Department of Veterans Affairs , Boston , MA , USA.
\end{abstract}

BACKGROUND: Personalized care planning is a patientcentered, whole-person approach to treatment planning. Personalized care plans improve patient outcomes and are now mandated for chronic care management reimbursement. Yet guidance on how to best implement personalized care planning in practice is limited.

OBJECTIVE: We examined the adoption of personalized care planning in patient-centered medical home (PCMH) clinics to identify processes and organizational characteristics that facilitated or hindered use in routine practice. DESIGN: Qualitative multiple-case study design. We conducted site visits at PCMH clinics in four US Veterans Health Administration (VHA) medical centers. Data included 10 general clinic observations, 34 direct observations of patient-provider clinical encounters, 60 key informant interviews, and a document review. Data were analyzed via qualitative content analysis using a priori and emergent coding.

PARTICIPANTS: Employees and patients participating in clinical encounters in PCMH clinics at four VHA medical centers.

KEY RESULTS: Each clinic used a distinct approach to personalized care planning: (1) distributed tasks approach; (2) two-tiered approach; (3) health coaching approach; and (4) leveraging a village approach. Each varied in workflow, healthcare team utilization, and degree of integration into clinical care. Across sites, critical components for implementation included expanding planning beyond initial assessment of patient priorities; framing the initiative for patients; using a team-based approach to care plan development and updates; using communication mechanisms beyond the electronic health record; and engaging stakeholders in implementation planning.

Prior Presentations This paper has not previously been presented.

Received March 1, 2019

Revised July 25, 2019

Accepted September 16, 2019

Published online October 24, 2019
CONCLUSIONS: Personalized care planning is a novel patient-centered practice, but complicated to implement. We found variation in effective implementation and identified critical components to structuring this practice in a manner that engages patients in treatment aligned with personal priorities. Primary care practices seeking to implement personalized care planning must go beyond simply asking patients a series of questions to establish a plan. They must also engage team members in plan development, communication, and dissemination.

KEY WORDS: patient-centered care; qualitative research; Veterans; primary care.

J Gen Intern Med 35(2):428-36

DOI: $10.1007 / \mathrm{s} 11606-019-05418-4$

(c) Society of General Internal Medicine (This is a U.S. government work and not under copyright protection in the U.S.; foreign copyright protection may apply) 2019

\section{INTRODUCTION}

Personalized care planning, a process to collaboratively develop care plans tailored to patient priorities and social contexts, is increasingly important to providing high-quality, patientcentered care. ${ }^{1-3}$ Despite varying contents and terminologies (e.g., personalized care plans, comprehensive shared care plans), these approaches incorporate common elements including (a) patient-provider discussions to identify goals; (b) development of holistic plans that attend to clinical and nonclinical needs; and (c) mechanisms to share plans across providers to coordinate care. ${ }^{1}$ Consonant with goal-directed care, these plans are designed to align healthcare with what matters most to patients, shifting away from a disease-oriented paradigm. $^{4-7}$ Often used with medically complex patients, personalized care plans have been effective in improving outcomes when integrated into routine care ${ }^{8}$ and are now mandated by the Centers for Medicare and Medicaid Services for chronic care management reimbursement. ${ }^{9}$ 


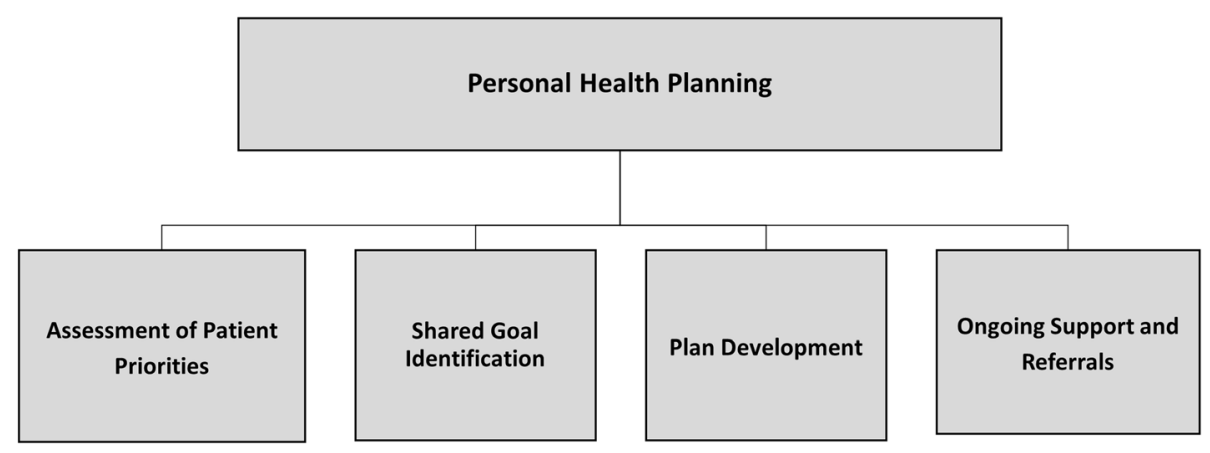

Figure 1 Components of personal health planning. Adapted from VHA Office of Patient-Centered Care and Cultural Transformation.

In 2013, the US Veterans Health Administration (VHA) initiated a version of personalized care planning known as personal health planning (PHP). Consistent with approaches described above, PHP is a mechanism to collaboratively develop care plans aligned with patients' personal goals and social contexts. In its idealized form, PHP is a process involving assessment of patients' priorities, shared goal identification, and services supporting goal attainment (Fig. 1). Key features include patient-centered communication, incorporation of nonclinical domains like spirituality or relationships, and care coordination across the healthcare system. ${ }^{10}$ Adoption is underway across VHA, often in primary care clinics organized according to the patient-centered medical home (PCMH) model. ${ }^{11}$ Given PCMH's emphasis on whole-person care, patientcentered dialogues, and care tailored to patient preferences, these settings align well with the goals of PHP and conceptually are an ideal match for PHP implementation. ${ }^{12-16}$

Yet integrating personalized care planning into routine practice is not well understood and may present considerable challenges. ${ }^{6}$ Unlike implementing direct-care guidelines such as disease screening or surgical checklists, PHP requires a cultural shift to shape care around patient priorities. ${ }^{3,6,10}$ This shift is similar to the implementation of other complex initiatives including $\mathrm{PCMH}$, requiring buy-in, role negotiation, coordination, and integration with clinical informatics. ${ }^{17-23}$ Although research on challenges specific to personalized care planning implementation is limited, one feasibility study of PHP identified similar challenges. ${ }^{10}$

Therefore, we sought to characterize how personalized care planning was structured and implemented early in VHA's adoption of this practice. What organizational characteristics facilitated implementation, and which provided challenges? We examine PHP adoption in four VHA PCMH clinics to provide insights into healthcare organizations seeking to incorporate similar patient-centered care practices into routine care.

\section{METHODS}

\section{Study Design}

We used a qualitative multiple-case study design ${ }^{24-26}$ to examine PHP implementation in primary care at four VHA hospitals. Consistent with case study approaches, ${ }^{24,}{ }^{26}$ we treated each site's implementation of PHP in one PCMH clinic as a case. We use the terms case, site, and clinic interchangeably. We conducted direct observations of care and key informant interviews, and collected documents relevant to PHP to provide in-depth understanding of the organizational context and adoption approach at each site. As this project was intended to inform VHA operations on PHP implementation, the Bedford VHA Hospital Institutional Review Board designated this study quality improvement, exempting it from further oversight.

\section{Recruitment and Participants}

We selected four sites in collaboration with the national office leading PHP implementation based on program robustness, including PHP documentation in the electronic health record (EHR), programs running for at least 1 year, and PHPs conducted with a general patient population. We worked with individuals leading implementation at each site to coordinate a multi-day visit. Clinic employees and patients were invited to participate. We informed individuals that participation was voluntary, was confidential, and would not impact their employment or (for patients) their healthcare. Assent was obtained from all participants.

\section{Data Collection}

During 2-3-day site visits between April 2014 and June 2015, investigators conducted (a) general clinic observations; (b) direct observations of clinical encounters; (c) semi-structured interviews with clinic leadership, PCMH team members, other clinic staff, and patients; and (d) review of PHP-related documents. Investigators spent each site visit day in the clinics, conducting observations and inviting clinic employees and a convenience sample of patients present that day to participate in interviews. They also requested copies of PHP-related documents used in the clinic, including EHR templates, and noted posted media about PHP, photographing clinic spaces when possible. Table 1 describes the data collected to support each case. Observations were recorded in field notes to capture key 
Table 1 Data Collected to Support Each Case

\begin{tabular}{|c|c|c|c|c|}
\hline & Case 1 & Case 2 & Case 3 & Case 4 \\
\hline $\begin{array}{l}\text { Types of general } \\
\text { clinic observations }\end{array}$ & $\begin{array}{l}3 \text { field notes describing: } \\
\text { a. Tour of clinic space } \\
\text { b. Waiting room } \\
\text { observations } \\
\text { c. Observations of } \\
\text { patient flow through } \\
\text { clinic }\end{array}$ & $\begin{array}{l}3 \text { field notes describing: } \\
\text { a. Tour of clinic and } \\
\text { nearby space } \\
\text { b. Waiting room } \\
\text { observation } \\
\text { c. Observation of } \\
\text { patient flow through } \\
\text { clinic }\end{array}$ & $\begin{array}{l}2 \text { field notes describing: } \\
\text { a. Tour of clinic space } \\
\text { b. Waiting room } \\
\text { observation } \\
\text { c. Observation of patient } \\
\text { flow through clinic }\end{array}$ & $\begin{array}{l}2 \text { field notes describing: } \\
\text { a. Tour of clinic space and } \\
\text { co-located services } \\
\text { b. Observation of patient flow } \\
\text { through clinic } \\
\text { c. Observation of patient } \\
\text { check-in/check-out activities }\end{array}$ \\
\hline $\begin{array}{l}\text { Observed clinical } \\
\text { encounters }\end{array}$ & 8 & 13 & 4 & 9 \\
\hline $\begin{array}{l}\text { Interviews with } \\
\text { employees }\end{array}$ & 10 & 10 & 13 & 15 \\
\hline $\begin{array}{l}\text { Interviews with } \\
\text { patients }\end{array}$ & 3 & 3 & 4 & 2 \\
\hline $\begin{array}{l}\text { Types of documents } \\
\text { reviewed }\end{array}$ & $\begin{array}{l}\text { PHP template print-out } \\
\text { from EHR } \\
16 \times 20 \text { posters about PHP } \\
\text { hung in exam rooms } \\
\text { Print-outs of patient-facing } \\
\text { letters and materials }\end{array}$ & $\begin{array}{l}\text { Framed PHP handout in } \\
\text { each exam room } \\
\text { PHP-related brochures in } \\
\text { waiting room }\end{array}$ & $\begin{array}{l}\text { PHP advertising materials } \\
\text { posted on health coach office } \\
\text { door }\end{array}$ & $\begin{array}{l}\text { EHR template } \\
\text { PHP worksheet completed by } \\
\text { patients }\end{array}$ \\
\hline
\end{tabular}

aspects of PHP implementation, communication about PHP, and patient-provider interactions. ${ }^{27}$ Interviews focused on experiences with PHP, adoption facilitators/ barriers, integration with existing clinical practices, and the clinical team's role in PHP.

\section{Analysis}

We conducted a directed content analysis ${ }^{28}$ using a priori codes based on principles of patient-centered care. ${ }^{29}$ Emergent categories captured additional content relevant to PHP adoption and processes. Six team members coded data in pairs, by site, sorting data into categories to capture relevant content. The entire team discussed coding to ensure consensus. Consistent with case study methodology, ${ }^{25,26}$ we developed a synthesis for each case by reviewing individual data summaries in coding categories, using constant comparison and summarizing findings for each site. Finally, we compared caselevel summaries to understand differences in implementation between sites.

\section{RESULTS}

We identified four distinct approaches to implementing PHP at the sites studied: (1) distributed tasks approach; (2) two-tiered approach; (3) health coaching approach; and (4) leveraging a village approach. To characterize each approach, we describe three domains that varied among the sites: clinic context, PHP workflow, and PHP integration (the extent to which PHP was incorporated into clinical care). Findings from general observations $(n=10)$, direct observations of clinical encounters $(n=$ $34)$, semi-structured interviews $(n=60)$, and PHP-related documents $(n=7)$ are presented below. Some quotations are included to illustrate specific points. Table 2 provides an overview of the PHP approach at each site.

All four clinics were selected by site leadership to implement PHP, with discretion in how to locally operationalize the initiative. Each clinic comprised multiple PCMH teams that included a clerk, nursing assistant (NA), nurse (RN), and primary care provider (PCP). Other professionals (e.g., social workers, clinical pharmacists, nutritionists) worked across teams. All clinics retained the components of the PHP model (Fig. 1) including making referrals to known service providers within and outside of the clinic to help patients achieve selected goals. Sites relied on templated progress notes in the EHR to share PHPs. Finally, all sites received support from the national office leading PHP via monthly calls and a centralized website.

\section{Case 1-Distributed Tasks Approach}

Context. This Southwestern PCMH clinic received national funding to promote patient-centered care initiatives including PHP. Facility leadership selected this clinic to implement PHP, perceiving this newly opened clinic as an opportunity to test new programs. Staff input on PHP adoption was incorporated through staff-wide meetings.

Workflow. Patients were chosen in advance for PHP; the nurse reported that she "scrubbed" the appointment list, identifying patients she subjectively thought would be interested in or benefit from a PHP. For selected patients, PHP development was distributed across the PCMH team, engaging all members except the clerk. The nursing assistant would read questions from an EHR template to assess patient priorities and patient self-ratings of current and desired health status. The RN used patient responses documented in the EHR to collaboratively identify goals and develop an action plan. 
Table 2 PHP Approach in Four VHA Primary Care Clinics

\begin{tabular}{|c|c|c|c|c|}
\hline & Case 1 & Case 2 & Case 3 & Case 4 \\
\hline Geographic & Urban & Urban & Urban & Semi-rural \\
\hline location & Southwest & Northeast & Midwest & Pacific Northwest \\
\hline Hospital & $\begin{array}{l}\text { Stand-alone primary care } \\
\text { clinic affiliated with a } \\
\text { large hospital }\end{array}$ & $\begin{array}{l}\text { Primary care clinic focused } \\
\text { on wellness embedded in a } \\
\text { large hospital }\end{array}$ & $\begin{array}{l}\text { Primary care clinic embedded } \\
\text { in a large hospital }\end{array}$ & $\begin{array}{l}\text { Stand-alone clinic offering } \\
\text { primary care and mental health } \\
\text { services affiliated with a small } \\
\text { hospital }\end{array}$ \\
\hline $\begin{array}{l}\text { PCMH teams in } \\
\text { clinic studied }\end{array}$ & $\begin{array}{l}5 \text { PCMH teams } \\
\text { Other staff: } \\
\text { Social work } \\
\text { Nutrition } \\
\text { PharmD }\end{array}$ & $\begin{array}{l}5 \text { PCMH teams } \\
\text { Other staff: } \\
\text { Health coach } \\
\text { Social work } \\
\text { PharmD } \\
\text { Acupuncture }\end{array}$ & $\begin{array}{l}12 \text { PCMH teams } \\
\text { Other staff: } \\
\text { Health coach } \\
\text { RN care managers } \\
\text { Social work } \\
\text { Nutrition } \\
\text { PharmD }\end{array}$ & $\begin{array}{l}4 \text { PCMH teams } \\
\text { Other staff: } \\
\text { PharmD } \\
\text { Mental health } \\
\text { Nutrition }\end{array}$ \\
\hline PHP workflow & $\begin{array}{l}\text { EHR template } \\
\text { Structured assessment } \\
\text { questions } \\
\text { Referrals from } \\
\text { pre-existing list }\end{array}$ & $\begin{array}{l}3 \text { questions to identify } \\
\text { priorities for all patients } \\
\text { Full plan for subset of } \\
\text { patients by health coach } \\
\text { Health coaching to execute } \\
\text { plan }\end{array}$ & $\begin{array}{l}\text { Health coaching referrals to } \\
\text { establish PHP and execute plan }\end{array}$ & $\begin{array}{l}\text { Worksheet completed at check-in } \\
\text { Worksheet reviewed by team } \\
\text { members } \\
\text { Referrals from pre-existing list }\end{array}$ \\
\hline $\begin{array}{l}\text { Involved team } \\
\text { members }\end{array}$ & $\begin{array}{l}\text { Nursing assistant } \\
\text { RN } \\
\text { PCP }\end{array}$ & $\begin{array}{l}\text { PCP } \\
\text { Health coach }\end{array}$ & $\begin{array}{l}\text { Health coach } \\
\text { RN care manager }\end{array}$ & $\begin{array}{l}\text { Clerk } \\
\text { Nursing assistant } \\
\text { RN } \\
\text { PCP } \\
\text { Outside providers }\end{array}$ \\
\hline $\begin{array}{l}\text { Primary } \\
\text { responsibility }\end{array}$ & Shared across team & Health coach & Health coach & Clerk \\
\hline $\begin{array}{l}\text { PHP plan } \\
\text { dissemination }\end{array}$ & $\begin{array}{l}\text { Team: EHR } \\
\text { Outside clinic: EHR } \\
\text { consult or not shared }\end{array}$ & $\begin{array}{l}\text { Team: EHR, huddles (rarely) } \\
\text { Outside clinic: EHR, phone }\end{array}$ & $\begin{array}{l}\text { Team: EHR, shared } \\
\text { appointments } \\
\text { Outside clinic: EHR }\end{array}$ & $\begin{array}{l}\text { Team: EHR, worksheet } \\
\text { Outside team: EHR, shared clinic } \\
\text { space }\end{array}$ \\
\hline $\begin{array}{l}\text { EHR integration } \\
\text { of PHP }\end{array}$ & $\begin{array}{l}\text { PHP progress notes } \\
\text { accessible to all staff }\end{array}$ & $\begin{array}{l}\text { PHP progress notes } \\
\text { accessible to all staff }\end{array}$ & $\begin{array}{l}\text { PHP progress notes accessible } \\
\text { to all staff and a link to the } \\
\text { PHP on the home screen }\end{array}$ & $\begin{array}{l}\text { PHP progress notes accessible to } \\
\text { all staff }\end{array}$ \\
\hline
\end{tabular}

The PCP then briefly reviewed the plan with the patient and approved referrals. Plans were largely based on available VHA and community-based referral options, selected from an existing list.

Integration. PHP was well-incorporated into clinical routines, occurring alongside other tasks. For example, we observed the NA seamlessly move from history-taking and asking prevention questions (e.g., seatbelt use) into asking PHP assessment questions. However, the contrast between routine clinical versus self-reflective questions (e.g., "what brings you joy?") were unexpected. Several patients were visibly surprised and even tearful as they self-reflected, with one patient later reporting the "personal (questions)...caught me off guard." Despite PHP incorporation into clinical routines, we observed care to be minimally organized around patient priorities, including a fixed approach for referrals to address selected goals. For example, all patients observed were referred to a weight loss program, despite only one specifying weight management as his goal. Although PCPs reviewed plans and approved referrals, we observed few conversations with patients about their priorities. Similarly, despite multiple team members engaged in PHP development, we observed minimal communication about PHP among team members. Staff described limited communication with services to which patients had been referred, hindering knowledge of whether patients were receiving adequate support to reach goals. Finally, while posters with PHP-related information were ubiquitous, patients reported unfamiliarity with the initiative.

\section{Case 2-Two-Tiered Approach}

Context. This recently redesigned PCMH clinic in a large Northeastern hospital also received national funding to promote patient-centered care. In addition to common PCMH staff, this site employed a health coach to support patients. ${ }^{30}$,

${ }^{31}$ Hospital leadership selected this clinic for PHP as part of its cultural transformation to emphasize wellness. Leadership provided organizational supports including policies to ease providers' administrative responsibilities. Staff received mentoring in patient-centered communication, including PHP, during a weekly half-day in-service.

Workflow. PHP occurred through a two-tiered approach. First, PCPs would routinely ask all patients three questions to assess patient priorities, gauge patient perceptions of health, 
and explore interest in health coaching. The health coach would then work with interested patients to develop a PHP. She oriented patients to this process by describing it as "identify(ing) hurdles to help you be your best self." Once completed, the health coach would provide ongoing support, refer patients for services, and regularly check-in. She characterized her work as the "umbrella" under which patients' needs were addressed.

Integration. We observed that most PCPs incorporated the three questions into clinical encounters but varied in their comfort initiating these conversations. Sometimes the questions were "tacked on" at the end of the encounter, visibly confusing patients who felt they had already expressed their concerns (e.g., pain management). Care was variably tailored to patient priorities: in our observations, some providers and the health coach exemplified patient-centered interactions; others retained provider-driven approaches. Within-team communication about PHP was limited. While problem-solving around general PHP use was explored during weekly in-services, participants reported rarely discussing individual PHPs during smaller team huddles. The health coach shared PHPs with referral services via phone and EHR to coordinate care.

\section{Case 3-Health Coaching Approach}

Context. Like site 2, this large Midwestern PCMH clinic employed a health coach. It additionally utilized RN care managers to provide chronic disease management services. The impetus for PHP arose from a regional effort to promote relationship-based care, a model that emphasizes patientcentered communication and patient-provider relationships. ${ }^{32}$ A nurse executive led PHP adoption, working closely with the health coach.

Workflow. PCPs identified patients with chronic conditions whom they felt would benefit from PHP. Receptive patients were referred to the health coach, who developed PHPs. He also provided ongoing support to facilitate goal achievement and linked patients with clinical and non-clinical services. RN care managers from two PCMH teams partnered closely with the health coach to develop PHPs for shared patients.

Integration. PHP was fully incorporated into the health coach's work and PHP posters were hung by his office. While the RN care managers routinely aligned their care with patients' PHPs, we observed little evidence of integration elsewhere. The health coach was primarily responsible for PHP, with staff members noting that PHP would likely end if he left. Communication was limited, with the health coach reporting rare opportunities to share PHPs with PCMH team members. He felt regularly excluded from huddles due to a lack of recognition of his value as a paraprofessional, describing himself as "gum on the bottom of a shoe" in the eyes of most of PCPs. We also found varied awareness of PHP among providers to whom patients were referred. For example, a social worker was unfamiliar with PHP. Others with familiarity reported rarely aligning care with
PHPs. For example, a clinical pharmacist described looking for PHPs only in "cricket situations" when patients didn't "volunteer" information. Instead, providers to whom patients were referred developed provider-driven care plans in accordance with their scopes of practice: "[My] plan has more to do with the goals that we actually set for the patients... [We] make sure that they're onboard...I mean I'm never going to tell a patient, 'You need to do this,' without them....acquiescing" (nutritionist).

\section{Case 4-Leveraging a Village Approach}

Context. This semi-rural Pacific Northwest PCMH clinic shared space with mental health and nutrition services, facilitating awareness of PHP. Efforts were underway to have clerks who traditionally filled clerical roles be involved in PHP, even training them as paraprofessional health coaches. PHP was blended with other health promotion activities, and adoption was led by a nurse executive and health promotion program manager. Staff described involvement in adoption planning to make the process "patient-friendly."

Workflow. PHP was facilitated through a standardized form probing patient priorities and interest in existing referral options. Clerks introduced the concept and patients completed the form independently preceding the visit. Staff then reviewed the form with the patient during the encounter, initiating referrals based on the patient's responses. Upon check-out, the clerk revisited the plan developed to ensure patient understanding and awareness of referrals. The RN later called patients to discuss their PHP.

Integration. Clerks introduced PHP to patients as a new way of practicing healthcare, framing PHP as a shift to patient-driven care, where "if we know what matters most to you, then we can make it what matters most to us too." While PCPs reported using the form in clinical encounters, our observations revealed inconsistencies: not all providers viewed the form or used it in treatment planning. Further, the list of referral options was not always responsive to patients: we observed some patients decline PHP due to lack of interest in available services. Communication about established PHPs varied. Clerks and the RN reviewed progress with patients, yet PHP was largely absent from patient-PCP discussions and team huddles. The clinic's medical director did not view PHPs in the EHR, expressing uncertainty about where to look. Unlike other clinics, referral providers were familiar with PHP and used it to guide care. For example, a mental health practitioner described reviewing PHPs to orient herself to patients' goals, social context, and interests, allowing her to align treatment.

\section{Themes Across Cases}

Although sites differed in their approach to PHP, we identified five overarching areas for facilitating implementation: using an iterative approach; framing the PHP; using a team-based approach; communicating beyond 
the EHR; and team engagement in implementation planning.

Using an Iterative Approach. When sites used PHP as an iterative process, they achieved better incorporation of patient goals in care planning. We found that sites 2 and 3 achieved richer PHP integration through their respective approaches, where plans were developed and revised as patients' lives evolved. An embedded health coach followed patients and provided ongoing support to achieve goals. Alternatively, sites 1 and 4 treated PHP development like other clinical tasks, lacked follow-up on patient goals, and based plans on pre-identified referral options.

Framing the PHP. Sites that framed PHP better oriented patients to its purpose and engaged them at the start. At site 4, clerks described PHP to patients upon giving them the PHP form in advance of their appointment, while health coaches at sites 2 and 3 spent time introducing patients to the concept of PHP and health coaching services. In contrast, when framing was absent, patients struggled to respond to PHP questions or identify personal priorities and goals. At site 2 , in the absence of the health coach, we observed a provider asked the "what really matters" question at the end of the clinical encounter. This resulted in confusion for the patient who replied that his previously discussed pain was what mattered. A similar pattern was found at site 1 , where patient confusion and distress were observed when PHP questions were asked without adequate framing.

Using a Team-Based Approach. We identified two disparate styles to PHP development in the context of team-based care: spreading responsibility across team members (sites 1 and 4) versus reliance on health coaches (sites 2 and 3). When PHP was not addressed by all team members (sites 2 and 3), we found that clinical conversations by uninvolved healthcare workers failed to acknowledge and align treatment with patient priorities. Alternatively, at site 3, where RN care managers were included in PHP conversations, we observed strong alignment between care and patient priorities. Simultaneously, at this same site, the failure of the nutritionist and clinical pharmacist to utilize PHPs to guide care planning resulted in unaligned, provider-driven treatment.

Communicating Beyond the EHR. We found important communication gaps at all sites despite consistent EHR documentation. Across all sites, the EHR was the primary communication mechanism, yet alone was insufficient. Discussions about patients' PHPs were excluded from huddles, team meetings, and other routine team communications at all sites, unless informally initiated by the person charged with leading PHP. Subsequently, not all team members were familiar with patient goals or developed plans. At site 3, PCPs were unfamiliar with the process, which they perceived as the responsibility of the health coach; at site 4, not all PCPs were aware they could view the PHP in the EHR.

Team Engagement for Implementation. Most sites engaged clinic staff in PHP design, facilitating its awareness and use. This was accomplished through half-day planning retreats, periodic staff meetings to review adoption challenges, and incorporation of ideas across all staff members (e.g., patientfriendly edits to the form used at site 4). Notably, however, PCPs across most sites were minimally engaged with implementation planning, resulting in less PHP familiarity and use.

\section{DISCUSSION}

We found substantial variation in PHP implementation in four VHA PCMH clinics, including variation in workflow, ownership and delegation, staff engagement, and utilization. Like PCMH reorganization, ${ }^{13}$ PHP was envisioned as a way to transform treatment planning. The approaches taken by the sites studied achieved varying degrees of success incorporating PHP into clinical routines, organizing care around patient priorities, and communicating about PHP. Even the early adopting sites with robust PHP practices profiled in our study faced challenges. Our findings provide several important insights into future adoption of personalized care planning programs like PHP.

Personalized care planning is more than a set of questions for patients to answer. It is a process to orient care around patient priorities, with follow-up conversations enabling plan revisions responsive to patients' evolving lives. ${ }^{1,2,10}$ Sites in our study variably achieved this spirit, with two sites accomplishing this goal via ongoing health coaching. The remaining sites approached PHP as a box to be checked, which did not always align with patient priorities. As we have described elsewhere, ${ }^{6,33}$ in the absence of broader efforts to transform culture, care planning initiatives like PHP are at risk of being implemented in a manner similar to other quality improvement tools such as clinical reminders or checklists. Our case study findings substantiate this argument. As primary care clinics adopt personalized care planning initiatives, conceptualizing planning as an iterative process that routinely engages patients in conversations about what really matters better aligns care with patients' needs. Some sites in our study subjectively selected patients perceived to be good candidates for PHP, perhaps due to limited time and resources. In an ideal world, all patients would have the opportunity to explore and share their health goals with providers, ensuring care that considers patients' life contexts. ${ }^{7,34}$ However, in contexts with limited resources, focusing PHP on patients with complex chronic conditions may be warranted.

Patient-centered care initiatives, like PHP, are distinctly different from other disease-centric programs. They necessitate different patient-provider interactions, recognizing patients as experts in their own lives and collaboratively engaging stakeholders, including patients and care team members alike, as partners. ${ }^{5}$ This may be very different for patients who are used to traditional, prescriptive care. Indeed, in our study, we found that patients were unaccustomed to this approach; lack of framing resulted in confusion and distress. Future PHP 
adoption efforts should attend to framing as a key component. Using clerks to introduce PHP, as one site in our study did, may help orient patients and unburden busy providers while achieving a key PCMH goal of optimizing staffs' responsibilities. ${ }^{35}$

We found that PHP adoption required an integrated, team-based approach consistent with the PCMH mod$\mathrm{el}^{36,37}$ for its successful incorporation into clinical care. Sites in our study took two overarching approaches to incorporating PHP in teams: one spread responsibility; the other centralized responsibility among health coaches. While spreading responsibility better engages all team members, it requires role shifts and communication to become fully integrated into care. This was difficult for the clinics in our study to achieve in practice. Alternatively, while placing responsibility on a single team member (e.g., health coach) created deeper collaboration with patients and facilitated patient goaldirected care, it failed to adequately engage the full team, particularly PCPs. With core principles of teambased care comprising mutual goals, role clarity, trust, and communication, ${ }^{22,} 37$ future implementation should carefully consider team-based approaches to develop and disseminate plans that engage but not overburden already busy members by identifying a PHP lead or point person within the team.

Communication is critical for coordination across healthcare systems, and informatics applications increasingly play a role in such efforts. ${ }^{38}$ The EHR is necessary to enable asynchronous coordination around personalized care plans. ${ }^{1,2}$ However, in our study, clinics' reliance on the EHR was insufficient to share PHPs across the team and coordinate care around patient priorities. Developing EHR mechanisms that better represent complex evolving patient goals and readily display this information is needed for successful PHP implementation. Moreover, if PHP is to truly become a living document that originates in primary care and is brought forward through all aspects of care, then healthcare systems must incorporate additional communication mechanisms to ensure shared awareness of patient goals. Incorporating discussions of PHP into team huddles may be one strategy to facilitate better communication. ${ }^{19}, 39$

Successful implementation of new practices requires buy-in among those tasked with delivery. When stakeholders are engaged in the design of new practice innovations, they may be more likely to adopt them. ${ }^{40,}{ }^{41}$ In our study, engaging clinic staff was critical to PHP implementation. Yet sites struggled to adequately engage PCPs in the PHP process, mirroring research on how demands faced by PCPs may limit engagement in transformational initiatives. ${ }^{13,22,39,42}$ This raises important questions for future research regarding the role of PCPs as team leaders in $\mathrm{PCMH}$ and related distribution of work when implementing PHP. Further, when providers both in and outside of the clinic have limited knowledge of PHP, patients may receive mixed messages about treatment priorities. Clinics seeking to implement initiatives like PHP should engage stakeholders early and continue to promote PHP once implemented.

\section{LIMITATIONS}

This study examined PHP adoption in only four VHA PCMH clinics, all utilizing different approaches to PHP. There are likely additional approaches to PHP implementation not captured in our study. Transferability of our findings to other sites will depend in part on similarities with the sites we describe here. Future research should examine personalized care planning adoption in other healthcare organizations, expand studies to include additional aspects of implementation such as cost, and test how variation in implementation relates to patient and organizational outcomes.

\section{CONCLUSION}

Personalized care planning has the potential to transform how healthcare is delivered, intimately engaging patients in their treatment and aligning care with their priorities. Yet providers are unlikely to be successful implementing personalized care planning on their own without broader infrastructure and cultural transformation initiatives to support its integration into care. As healthcare organizations continue to adopt these practices, attention must be given to planning as an ongoing process and framing this new approach for patients and providers alike. Implementation should include the healthcare team in program design, and thoughtfully engage them in the development, communication, and dissemination of personalized care plans. While embedding plans in the EHR is necessary, it is not enough to promote shared understanding and system-level coordination aligned with patient goals. Establishing patient and team-centered communication mechanisms will be critical to truly implementing personalized care plans as a patientcentered innovation in practice.

Acknowledgments: Thank you to Jeffrey Solomon, $\mathrm{PhD}$, for his assistance with data collection; Therasia Roland, MSW, for her assistance with data coding; and Juliet Wu, BS, for her assistance with manuscript preparation.

Corresponding Author: Rendelle E. Bolton, MPH, MSW, MA; Center for Evaluating Patient-Centered Care in VA, Center for Healthcare Organization and Implementation Research, Edith Nourse Rogers Memorial Veterans HospitalMemorial Veterans Hospital US Department of Veterans Affairs, 200 Springs Road, Bedford, MA 01730, USA (e-mail: Rendelle.Bolton@va.gov).

Funding Information This study was funded by the US Department of Veterans Affairs, Office of Patient-Centered Care and Cultural Transformation, and the Quality Enhancement 
Research Initiative (grant no. PCE13-001). Dr. Fix is a VA HSR\&D Career Development awardee at the Bedford VA (CDA no. 14-156).

\section{Compliance with Ethical Standards:}

As this project was intended to inform VHA operations on PHP implementation, the Bedford VHA Hospital Institutional Review Board designated this study quality improvement, exempting it from further oversight. Verbal assent was obtained from all participants.

Conflict of Interest: The authors declare that they do not have a conflict of interest.

Disclosure: The views expressed in this article are those of the authors and do not necessarily reflect the position or policy of the Department of Veterans Affairs or the US Government.

Prior Presentations: This paper has not previously been presented.

\section{REFERENCES}

1. Edwards ST, Dorr DA, Landon BE. Can Personalized Care Planning Improve Primary Care? JAMA. 2017;318(1):25-6. doi:https://doi.org/10. $1001 /$ jama.2017.6953

2. Baker A, Cronin K, Conway P, DeSalvo K, Rajkumar R, Press M. Making the comprehensive shared care plan a reality. New England Journal of Medicine Catalyst. 2016. http://catalyst.nejm.org/making-the-comprehensive-sharedcare-plan-a-reality/. Accessed 20 June 2017.

3. Sullivan SS, Mistretta F, Casucci S, Hewner S. Integrating social context into comprehensive shared care plans: A scoping review. Nurs Outlook. 2017;65(5):597-606. doi:https://doi.org/10.1016/j.outlook.2017.01.014

4. Tinetti ME, Naik AD, Dodson JA. Moving From Disease-Centered to Patient Goals-Directed Care for Patients With Multiple Chronic Conditions: Patient Value-Based Care. JAMA Cardiol. 2016;1(1):9-10. doi:https://doi.org/10.1001/jamacardio.2015.0248

5. Reuben DB, Tinetti ME. Goal-oriented patient care - an alternative health outcomes paradigm. N Engl J Med. 2012;366(9):777-9. doi:https://doi. org/10.1056/NEJMp1113631

6. Fix GM, Bolton RE, Bokhour BG. Challenges in Implementing Personalized Care Planning. JAMA. 2017;318(17):1713. doi:https://doi.org/10. 1001/jama.2017.14254

7. Mold JW, Blake GH, Becker LA. Goal-oriented medical care. Fam Med. 1991;23(1):46-51.

8. Coulter A, Entwistle VA, Eccles A, Ryan S, Shepperd S, Perera R. Personalised care planning for adults with chronic or long-term health conditions. Cochrane Database Syst Rev. 2015(3):CD010523. doi:https://doi.org/10.1002/14651858.CD010523.pub2

9. Centers for Medicare \& Medicaid Services (CMS), HHS. Medicare program; revisions to payment policies under the Physician Fee Schedule, Clinical Laboratory Fee Schedule, access to identifiable data for the Center for Medicare and Medicaid Innovation Models \& other revisions to Part B for CY 2015. Final rule with comment period. Fed Regist. 2014;79(219):67547-8010.

10. Simmons LA, Drake CD, Gaudet TW, Snyderman R. Personalized health planning in primary care settings. Fed Pract. 2016;33(1):27-34.

11. Schectman G, Stark R. Orchestrating large organizational change in primary care: the Veterans' Health Administration experience implementing a patient-centered medical home. J Gen Intern Med. 2014;29 Suppl 2:S550-1. doi:https://doi.org/10.1007/s11606-0142828-7

12. Rosland AM, Nelson K, Sun $\mathrm{H}$, et al. The patient-centered medical home in the Veterans Health Administration. Am J Manag Care. 2013;19(7):e263-72.

13. Nutting PA, Miller WL, Crabtree BF, Jaen CR, Stewart EE, Stange KC. Initial lessons from the first national demonstration project on practice transformation to a patient-centered medical home. Ann Fam Med. 2009;7(3):254-60. doi:https://doi.org/10.1370/afm. 1002
14. Martsolf GR, Alexander JA, Shi Y, et al. The patient-centered medical home and patient experience. Health Serv Res. 2012;47(6):2273-95 doi:https://doi.org/10.1111/j.1475-6773.2012.01429.x

15. Bitton A, Martin C, Landon BE. A nationwide survey of patient centered medical home demonstration projects. J Gen Intern Med. 2010;25(6):584-92. doi:https://doi.org/10.1007/s11606-010-1262-8

16. Jackson GL, Powers BJ, Chatterjee R, et al. The patient centered medical home. A systematic review. Ann Intern Med. 2013;158(3):169-78. doi:https://doi.org/10.7326/0003-4819-158-3-201302050-00579

17. Alidina S, Rosenthal M, Schneider E, Singer S. Coordination within medical neighborhoods: Insights from the early experiences of Colorado patient-centered medical homes. Health Care Manage Rev. 2016;41(2):101-12. doi:https://doi.org/10.1097/HMR. 0000000000000063

18. Farmer MM, Rose DE, Rubenstein LV, et al. Challenges facing primary care practices aiming to implement patient-centered medical homes. J Gen Intern Med. 2014;29 Suppl 2:S555-62. doi:https://doi.org/10 1007/s11606-013-2691-y

19. Cromp D, Hsu C, Coleman K, et al. Barriers and facilitators to teambased care in the context of primary care transformation. J Ambul Care Manage. 2015;38(2):125-33. doi:https://doi.org/10.1097/JAC. 0000000000000056

20. Shaller D. Patient-centered care: What does it take? New York, NY: Commonwealth Fund; 2007.

21. Luxford K, Safran DG, Delbanco T. Promoting patient-centered care: a qualitative study of facilitators and barriers in healthcare organizations with a reputation for improving the patient experience. Int $J$ Qual Health Care. 2011;23(5):510-5. doi:https://doi.org/10.1093/intqhc/mzr024

22. True G, Stewart GL, Lampman M, Pelak M, Solimeo SL. Teamwork and delegation in medical homes: primary care staff perspectives in the Veterans Health Administration. J Gen Intern Med. 2014;29 Suppl 2:S632-9. doi:https://doi.org/10.1007/s11606-013-2666-Z

23. Rodriguez HP, Giannitrapani KF, Stockdale S, Hamilton AB, Yano EM, Rubenstein LV. Teamlet structure and early experiences of medical home implementation for veterans. J Gen Intern Med. 2014;29 Suppl 2:S62331. doi:https://doi.org/10.1007/s11606-013-2680-1

24. Stake RE. Multiple Case Study Analysis. New York, NY: The Guilford Press; 2006

25. Creswell JW, Poth CN. Qualitative Inquiry and Research Design: Choosing Among Five Approaches. 4th ed. Thousand Oaks, CA: SAGE Publications, Inc.; 2018.

26. Yin RK. Case Study Research: Design and Methods. 4th ed. Thousand Oaks, CA: SAGE Publications, Inc.; 2009

27. Bernard HR. Field Notes: How to Take Them, Code Them, Manage Them Research Methods in Anthropology: Qualitative and Quantitative Approaches. 3rd ed. Walnut Creek, CA: AltaMira Press; 2002: 365-89.

28. Hsieh HF, Shannon SE. Three approaches to qualitative content analysis. Qual Health Res. 2005; 15:1277-88.

29. Mead N, Bower P. Patient-centredness: a conceptual framework and review of the empirical literature. Soc Sci Med. 2000;51(7):1087-110.

30. Wolever RQ, Simmons LA, Sforzo GA, et al. A systematic review of the literature on health and wellness coaching: defining a key behavioral intervention in healthcare. Glob Adv Health Med. 2013;2(4):38-57.

31. Olsen JM, Nesbitt BJ. Health coaching to improve healthy lifestyle behaviors: an integrative review. Am J Health Promot. 2010;25(1):e1-e12.

32. Koloroutis $\mathrm{M}$, Trout $\mathrm{M}$. See me as a person: Creating therapeutic relationships with patients and their families. Minneapolis, MN: Creative Health Care Management, Inc.; 2012.

33. Bokhour BG, Cutrona SL. Time to listen more and talk less. J Gen Intern Med. 2019;34(1): 1-2.

34. Sacristan J. Patient-centered medicine and patient-oriented research: improving health outcomes for individual patients. BMC Med Inform Decis Mak. 2013;13(1):6.

35. Solimeo SL, Stewart GL, Rosenthal GE. The Critical Role of Clerks in the Patient-Centered Medical Home. Ann Fam Med. 2016;14(4):377-9. doi:https://doi.org/10.1370/afm. 1934

36. Goldberg DG, Beeson T, Kuzel AJ, Love LE, Carver MC. Team-based care: a critical element of primary care practice transformation. Popul Health Manag. 2013;16(3): 150-6. doi:https://doi.org/10.1089/pop.2012.0059

37. Mitchell P, Wynia M, Golden R, et al. Core principles \& values of effective team-based health care. Washington, DC: Institute of Medicine; 2012.

38. Nazi KM, Hogan TP, Woods SS, Simon SR, Ralston JD. Consumer health informatics: engaging and empowering patients and families. In: Finnell 
J, Dixon B, editors. Clinical Informatics Study Guide: Text and Review. New York, NY: Springer; 2016: 459-500.

39. Rodriguez HP, Meredith LS, Hamilton AB, Yano EM, Rubenstein LV. Huddle up!: The adoption and use of structured team communication for VA medical home implementation. Health Care Manage Rev. 2015;40(4):286-99. doi:https://doi.org/10.1097/HMR.0000000000000036

40. Wallerstein NB, Duran B. Using community-based participatory research to address health disparities. Health Promot Pract. 2006;7(3):312-23.

41. Minkler M, Salvatore A. Participatory approaches for study design and analysis in dissemination and implementation research. In
Brownson R, Colditz G, Proctor E, editors. Dissemination and implementation research in health: Translating science to practice. New York, NY: Oxford University Press; 2012: 192-212.

42. Fernald DH, Deaner N, O’Neill C, Jortberg BT, Degruy FV, Dickinson WP. Overcoming early barriers to $\mathrm{PCMH}$ practice improvement in family medicine residencies. Fam Med. 2011;43(7):503-9.

Publisher's Note Springer Nature remains neutral with regard to jurisdictional claims in published maps and institutional affiliations. 